\title{
Acetazolamide: a second wind for a respiratory stimulant in the intensive care unit?
}

\author{
Nicholas Heming*1 ${ }^{* 1}$ Saïk Urien² and Christophe Faisy ${ }^{1}$
}

\begin{abstract}
Patients with chronic obstructive pulmonary disease (COPD) are affected by episodes of respiratory exacerbations, some of which can be severe and may necessitate respiratory support. Prolonged invasive mechanical ventilation is associated with increased mortality rates. Persistent failure to discontinue invasive mechanical ventilation is a major issue in patients with COPD. Pure or mixed metabolic alkalosis is a common finding in the intensive care unit (ICU) and is associated with a worse outcome. In patients with COPD, the condition is called post-hypercapnic alkalosis and is a complication of mechanical ventilation. Reversal of metabolic alkalosis may facilitate weaning from mechanical ventilation of patients with COPD. Acetazolamide, a non-specific carbonic anhydrase inhibitor, is one of the drugs employed in the ICU to reverse metabolic alkalosis. The drug is relatively safe, undesirable effects being rare. The compartmentalization of the different isoforms of the carbonic anhydrase enzyme may, in part, explain the lack of evidence of the efficacy of acetazolamide as a respiratory stimulant. Recent findings suggest that the usually employed doses of acetazolamide in the ICU may be insufficient to significantly improve respiratory parameters in mechanically ventilated patients with COPD. Randomized controlled trials using adequate doses of acetazolamide are required to address this issue.
\end{abstract}

\section{Introduction}

Sulfanilamide, one of the first oral antibiotics, was initially used more than 70 years ago. It was observed that the drug induced both metabolic acidosis and hyperventilation, owing to renal carbonic anhydrase (CA) inhibition. Synthesis of stronger CA inhibitors yielded the

*Correspondence: nicholas.heming@orange.fr

'Medical Intensive Care Unit, European Georges Pompidou Hospital (AP-HP), Université Paris Descartes, Sorbonne Paris Cité, 20 rue Leblanc, 75908 Paris, France Full list of author information is available at the end of the article more potent sulfonamide, acetazolamide. Pure or mixed metabolic alkalosis is a common finding in the intensive care unit (ICU) and is associated with a detrimental outcome. By inducing metabolic acidosis, acetazolamide might facilitate discontinuation from mechanical ventilation in patients who suffer from chronic obstructive pulmonary disease (COPD) and who have also developed metabolic alkalosis. The evidence supporting the administration of acetazolamide in such a situation, however, remains sparse.

\section{Chronic obstructive pulmonary disease in the intensive care unit}

COPD is a progressive and irreversible disease that is defined by an expiratory airflow limitation and caused by a mixture of small-airway disease and lung parenchyma destruction [1]. Cigarette smoking is the most common risk factor for developing the disease. COPD is a major public health issue owing to the associated morbidity and mortality. In the US, COPD is the fourth leading cause of morbidity and mortality [1]. The natural history of the disease is marked by the occurrence of exacerbations affecting the prognosis of patients [2]. COPD is a frequent cause of emergency referrals and ICU hospitalization [3,4]. Initiation of non-invasive mechanical ventilation in the setting of COPD exacerbations reduces mortality [5]. However, initiation of invasive mechanical ventilation may be necessary (for instance, after the failure of an initial trial of non-invasive mechanical ventilation). Acute COPD exacerbations are associated with in-hospital mortality rates of between $24 \%$ and $32 \%$ $[4,6]$. Invasively ventilated patients with COPD are at a high risk of prolonged mechanical ventilation [7] and at a high risk of persistent weaning failure. Prolonged invasive mechanical ventilation is associated with an increased hospital mortality $[8,9]$.

A series of factors are associated with persistent weaning failures from mechanical ventilation in patients with COPD: age, severity of initial presentation, associated diseases such as left ventricular dysfunction, metabolic disorders, critical illness polyneuromyopathy, and the existence of ventilator-associated pneumonia [7,9]. Weaning from mechanical ventilation of patients with 
COPD appears to be more successful when undertaken in specialist multidisciplinary wards [10]. Metabolic alkalosis, a common condition in the ICU, is reported to be associated with difficulties in obtaining a successful weaning from mechanical ventilation, especially in patients with COPD $[11,12]$.

\section{Metabolic alkalosis in the intensive care unit}

The acid-base equilibrium is regulated in the healthy subject by the kidney and the lungs. A disruption of this equilibrium can be due to an alteration of lung function (causing respiratory acidosis or alkalosis by hypo- or hyperventilation) or an alteration of kidney function (inducing an acidic or alkaline charge causing metabolic acidosis or alkalosis) or both $[13,14]$. Respiratory acidosis and metabolic alkalosis are the two main acid-base disturbances found in patients with COPD during respiratory exacerbations. Metabolic alkalosis results when the $\mathrm{H}^{+}$concentration in the extracellular compartment is decreased by a loss of non-carbonic acid or an increase in alkali. The treatment of chronic carbonic dioxide retention frequently induces metabolic alkalosis, also known as post-hypercapnic alkalosis. It is a state of persistent metabolic alkalosis after the return of arterial partial pressure of carbon dioxide $\left(\mathrm{PaCO}_{2}\right)$ to baseline [11]. Mixed acid-base balance disturbances (the association of chronic respiratory acidosis and metabolic alkalosis) can also be observed. Indeed, in mechanically ventilated patients with $\mathrm{COPD}$, the most frequently observed acid-base disorders are mixed $[15,16]$. In this context, respiratory acidosis is the consequence of hypercapnia. Respiratory acidosis can be acute or chronic, depending on renal adaptation. In patients with both COPD and respiratory exacerbation, hypercapnia induces an acidic change of the extracellular compartment, a lowering of arterial $\mathrm{pH}$, and an excess of serum bicarbonate.

Metabolic alkalosis is a common disorder in the critically ill and is often associated with other metabolic anomalies (hypokalemia, hypomagnesemia, hypophosphatemia, and hypoalbuminemia) [17,18]. Metabolic alkalosis in patients affected by COPD may diminish the activity of the central nervous respiratory command center and cardiac output $[19,20]$. In the ICU, metabolic alkalosis has been shown to inhibit the dissociation of oxyhemoglobin and to lead to the development of hypokalemia and hypophosphatemia $[19,20]$. It has also been suggested that metabolic alkalosis plays a role in prolonging the weaning period and in increasing morbidity and mortality in the critically ill, especially patients with COPD $[11,12,21]$. Other causes of failure to wean from mechanical ventilation are due to the respiratory control system, mechanics of the lung and chest wall, the respiratory muscles, the cardiovascular system, and gas-exchange properties of the lung [22].
Metabolic alkalosis is frequently iatrogenic, owing to the administration of diuretics or steroids, but may also be the result of permissive hypercapnia induced by lungprotective strategies and by digestive disorders such as vomiting or nasogastric suctioning [11]. Metabolic alkalosis can be treated, after correction of hypokalemia, by the administration of acetazolamide or chloride salts [23]. Correcting metabolic alkalosis may increase minute ventilation and improve oxygenation, which may in turn facilitate weaning from mechanical ventilation $[24,25]$.

\section{Carbonic anhydrase inhibitors}

CAs are metalloenzymes found in both the vegetable and the animal kingdoms [26]. The enzyme catalyzes an essential physiological function, the interconversion between carbon dioxide $\left(\mathrm{CO}_{2}\right)$ and bicarbonate [26]. The zinc ion of CAs plays an important role in catalysis. The active form of the CA enzyme is basic, and a hydroxide radical is bound to the zinc ion. Since the active form of the enzyme is a strong nucleophile, it attacks the $\mathrm{CO}_{2}$ molecule, forming bicarbonate coordinated to the zinc ion. The bicarbonate ion is then released after being replaced by a water molecule. The CA enzyme family is compromised in vertebrates of 16 isoforms. CA isoforms have wildly different subcellular and tissue distributions throughout the organism [27-29]. The enzyme plays an important role in the alveolocapillary transport of $\mathrm{CO}_{2}$, in the regulation of the acid-base and hydroelectric equilibrium, and in the control of respiration [30]. CA inhibitors include the classic inhibitor acetazolamide as well as a number of more recent drugs [31]. These drugs are used in varied situations such as in the treatment of hypertension, glaucoma, diabetes, and cancer [26]. All CA inhibitors possess a zinc-binding group by which the drug interacts with the metal ion of the enzyme. Acetazolamide, a sulfonamide derivative, is a nonselective inhibitor of the CA enzyme. Since obstructive pulmonary disease is complicated by an increase in arterial $\mathrm{CO}_{2}$ levels, the main isozymes of interest in the disease are CA II (which plays a role in regulating gas exchange in the lung and in the erythrocyte) and CA IV (which plays a role in bicarbonate reabsorption in the kidney but also in regulating gas exchanges in the lung) [26]. Acetazolamide might also modulate the activity of slowly adapting pulmonary stretch receptors (SARs) via the inhibition of CA. SARs seem to play a role in the control of respiratory rate and tidal volume [32]. Indeed, SARs play a role in evoking the Hering-Breuer inflation reflexes. This is characterized by an early termination of inspiration when the lungs are inflated and a prolongation of the expiratory pause when a prolonged inflation is applied at the end of inspiration [32]. The inhibition of SAR activity occurs during inhalation of $\mathrm{CO}_{2}$ [33,34]. In turn, the administration of acetazolamide attenuates or 
blocks the inhibitory effects of $\mathrm{CO}_{2}$ inhalation and could modulate the activity of SARs $[32,35]$. Acetazolamide is used as a respiratory stimulant in subjects with COPD [30]. The classic explanation of why acetazolamide acts as a respiratory stimulant is through the inhibition of the renal CA enzyme, which in turn induces a decrease of serum bicarbonate and serum $\mathrm{pH}$. The ensuing metabolic acidosis causes a stimulation of peripheral chemoreceptors (carotid artery) and central chemoreceptors (through the acidification of the cerebrospinal liquid), which in turn induces an increase in minute ventilation. However, the effect of CA inhibitors on ventilation and ventilator responses seems more complex [30]. For instance, the effect of the modulation of the activity of the SARs by acetazolamide in the airway remains largely unknown. Hypothetically, this modulation could induce a respiratorystimulating effect by increasing both respiratory rate and tidal volume. The tissue compartmentalization of $\mathrm{CA}$ isoforms and the low selectivity of acetazolamide may explain, in part, the complexity of the effect of the drug in patients with COPD $[30,36]$ and, in turn, might explain why the efficacy of acetazolamide is so moderate in the critically ill patient with COPD. An alternative reason could be that factors other than metabolic alkalosis are more important during discontinuation from mechanical ventilation.

Since acetazolamide is a non-specific CA inhibitor, the administration of the drug is susceptible to induce a host of varied physiological consequences on nervous conduction, ventilation control, oxygen transport and on diuresis. Acetazolamide also seems to have inhibiting effects at the neuromuscular level. Studying hypercapnic conditions in an animal model, Kiwull-Schone and colleagues [28] found that, after administration of low doses of acetazolamide, an increased neuronal drive was necessary to maintain a given tidal volume. Similarly, in healthy subjects, Brechue and colleagues [37] reported that acetazolamide inhibited the Achilles tendon-tap reflex and associated isometric force. Acetazolamide, administered at doses ranging from 250 to $500 \mathrm{mg}$ (3.5 to $7 \mathrm{mg} / \mathrm{kg}$ ), induces, at sea level, an increase in minute ventilation by $10 \%$ to $20 \%$ both at rest and during exercise in healthy subjects [38] and an increase in oxygen saturation of hemoglobin by $3 \%$ to $6 \%$ in subjects with hypoxemia $[20,30]$. The drug induces an alkaline diuresis by reducing the tubular reabsorption of bicarbonate and by inhibiting the distal secretion of $\mathrm{H}^{+}$. After administration of acetazolamide, $30 \%$ of filtered bicarbonate is eliminated in the urine, whereas the transepithelial transport of bicarbonate is reduced from $70 \%$ to $100 \%[39,40]$. Alkaline diuresis induced by acetazolamide is maximized at 24 hours and is associated with a urinary loss of bicarbonate of about 4 to $6 \mathrm{mmol} /$ $\mathrm{L}$, which in turn induces a decrease of blood $\mathrm{pH}$ by 0.05 to 0.1 units. The resulting metabolic acidosis stimulates peripheral and central chemoreceptors associated with an increase in minute ventilation. This respiratory response induces a decrease of $\mathrm{PaCO}_{2}$ of 5 to $6 \mathrm{~mm} \mathrm{Hg}$ (provided that there is no mechanical limitation to the increase of tidal volume or respiratory rate) [30]. According to Moviat and colleagues [41], the effect of acetazolamide is mediated by an increased renal excretion of strong ions (bicarbonates), a retention of chloride, and consequently a decrease in the strong ion difference defined by the equation $\left(\left[\mathrm{Na}^{+}\right]+\left[\mathrm{K}^{+}\right]+\right.$ $\left.\left[\mathrm{Mg}^{++}\right]+\left[\mathrm{Ca}^{++}\right]\right)-\left(\left[\mathrm{Cl}^{-}\right]+\left[\right.\right.$lactates $\left.\left.{ }^{-}\right]\right)$. This strong ion difference is one of the parameters that govern water dissociation and thus the serum concentration of $\mathrm{H}^{+}$.

\section{Pharmacology}

The plasma half-life of acetazolamide in the healthy subject is between 4 and 8 hours [42]. Absorption of the drug after an oral intake is very fast. Acetazolamide is eliminated mainly by the kidney and the liver. In case of renal or hepatic dysfunction, acetazolamide is therefore susceptible to accumulate [43].

Both furosemide and corticosteroids lessen the effect of acetazolamide on serum bicarbonate concentration. Indeed, both drugs induce metabolic alkalosis by stimulation of distal tubular $\mathrm{H}^{+}$secretion [11]. Additionally, acetazolamide and furosemide are transported by the same carrier-mediated mechanism from the plasma to their site of action localized at the luminal side of renal tubules [44]. In vitro, furosemide interacts with the CA enzyme at the same site as acetazolamide, potentially blocking the interaction between acetazolamide and the CA enzyme [27]. The respiratory effects of acetazolamide at low or moderate doses are well known, mainly in the healthy subject. The effect of acetazolamide is less well known in critically ill patients with COPD. Additionally, these patients often receive loop diuretics during the weaning period [15].

The drug is relatively safe; the main undesirable effects are hypersensibility, blood dyscrasias, dysthyroidism, and gout attacks. These undesirable effects, though potentially severe, are rare [45]. Acetazolamide in patients with cirrhosis is susceptible to induce or aggravate hepatic encephalopathy and therefore should be avoided [43]. Another potential complication of acetazolamide administration is an aggravation of hypercapnia because of red blood cell CA inhibition and impaired $\mathrm{CO}_{2}$ transport [46]. If the contraindications of the drug are respected, the only real issue faced by physicians in the ICU is hypokalemia. Therefore, blood chemicals should be monitored closely when acetazolamide is administered to the critically ill.

\section{Clinical data}

Vos and colleagues [47] showed that the administration of acetazolamide to patients with COPD improves 
arterial blood gas parameters without significantly changing minute ventilation. On the other hand, Swenson [30] and Teppema and Dahan [36] showed that acetazolamide increases minute ventilation by reducing excess base levels in the healthy subject. It has also been reported that non-responders to acetazolamide (defined by a reduction of $\mathrm{PaCO}_{2}$ of less than $5 \mathrm{~mm} \mathrm{Hg}$ ) have a more severe airflow limitation than responders [48]. This finding has not been confirmed in later studies [16].

Mazur and colleagues [49] assessed, in 40 invasively ventilated patients with both COPD or asthma and pure metabolic alkalosis, the effect of two dosing regimens of acetazolamide (500 mg per day versus $250 \mathrm{mg}$ four times per day) on the variations of bicarbonate over the course of 72 hours. A significant and lasting decrease of bicarbonate concentration was reported in both treatment groups. These results suggest that the pharmacological effect of acetazolamide lasts longer than expected from the plasma half-life of the drug (5 to 6 hours) in patients with both COPD and pure metabolic alkalosis. However, no clinically relevant endpoint was assessed in this study. It must also be noted that relatively few patients in the ICU were subject to a pure metabolic alkalosis [15]. Another study in a surgical ICU gave similar results when acetazolamide was administered at a dosage of $500 \mathrm{mg}$ per day [50].

Although acetazolamide is used to treat metabolic alkalosis, few data concerning the optimal dosage of the drug in the ICU are available. Usual dosage regimens vary from a single dose of 250 or $500 \mathrm{mg}$ per day $[49,50]$ to multiple doses of 250 or $500 \mathrm{mg}$ every 6 to 8 hours $[25,51]$. A recent case control observational study showed that acetazolamide, administered at a dosage of $500 \mathrm{mg}$ once a day during the weaning period from mechanical ventilation of patients with both COPD and pure or mixed metabolic alkalosis, significantly decreased the serum concentration of bicarbonate and increased the arterial partial pressure of oxygen/fraction of inspired oxygen $\left(\mathrm{PaO}_{2} / \mathrm{FiO}_{2}\right)$ ratio [15]. No effect on respiratory parameters such as minute ventilation or respiratory frequency was observed [15]. This decrease in bicarbonate concentration was statistically significant when compared with the control group but was of little clinical importance (less than $4 \mathrm{mmol} / \mathrm{L}$ ). Additionally, patients in the control group presented a slight decrease in serum bicarbonate concentration during the weaning period. The moderate effect of acetazolamide in lowering the serum bicarbonate concentration could explain the lack of efficacy of the drug in reducing $\mathrm{PaCO}_{2}$. Indeed, the pharmacodynamics of the drug in the ICU are not well known. The pharmacodynamics of acetazolamide were recently modeled in 68 mechanically ventilated patients who had COPD and who received single or multiple doses of up to $500 \mathrm{mg}$ of the drug during the weaning period [16]. The main co-variates of interest that were found to influence acetazolamide pharmacodynamics were the Simplified Acute Physiology Score II (SAPS II) at ICU admission, co-prescription of furosemide or corticosteroids, and serum concentrations of chloride. Additionally, co-administration of furosemide was found to significantly decrease bicarbonate elimination. In this pharmacodynamic model, acetazolamide induced a decrease in serum bicarbonate with a dose-response relationship, and the amount of acetazolamide found to induce $50 \%$ of the putative maximum effect was $117 \pm 21 \mathrm{mg}$. According to this model, an acetazolamide dosage of greater than $500 \mathrm{mg}$ twice daily is required to reduce serum bicarbonate concentrations of greater than $5 \mathrm{mmol} / \mathrm{L}$ in the presence of high serum chloride levels or co-administration of systemic corticosteroids or furosemide.

\section{Conclusions}

The efficacy of acetazolamide given to patients with both COPD and metabolic alkalosis during the weaning period remains unknown. In the ICU, the usually employed doses of the drug seem insufficient to have a meaningful effect on the serum concentration of bicarbonate. Surprisingly, up until now, no randomized controlled trial has been undertaken to assess the efficacy of the drug in patients with COPD in the ICU. To our knowledge, at least three randomized controlled studies that aim to determine the efficacy of acetazolamide given to patients with both COPD and metabolic alkalosis during the weaning period are under way (NCT01131377 and NCT01499485 [52] and a French trial that is not yet registered). From a clinical point of view, the compartmentalization of CAs is a promising new subject for the development of drugs modulating these enzymes, especially CA localized in the airway, the erythrocyte, and the diaphragm.

\section{Abbreviations \\ CA, carbonic anhydrase; $\mathrm{CO}_{2}$, carbon dioxide; $\mathrm{COPD}$, chronic obstructive pulmonary disease; ICU, intensive care unit; $\mathrm{PaCO}_{2}$, arterial partial pressure of carbon dioxide; SAR, slowly adapting pulmonary stretch receptor.}

\section{Competing interests}

The authors declare that they have no competing interests.

\section{Authors' contributions}

$\mathrm{NH}$ and CF were responsible for literature research, manuscript writing, and final approval. SU was responsible for final approval. All authors read and approved the final manuscript.

\section{Author details}

'Medical Intensive Care Unit, European Georges Pompidou Hospital (AP-HP), Université Paris Descartes, Sorbonne Paris Cité, 20 rue Leblanc, 75908 Paris, France. ${ }^{2}$ CIC-0109 Cochin-Necker Inserm, Unité de Recherche Clinique, Tarnier Hospital, (AP-HP) and E.A. 3620 Université Paris Descartes, Sorbonne Paris Cité, 27 Rue du Faubourg Saint-Jacques 75014 Paris, France.

Published: 7 August 2012 
References

1. Rabe KF, Hurd S, Anzueto A, Barnes PJ, Buist SA, Calverley P, Fukuchi Y, Jenkins C, Rodriguez-Roisin R, van Weel C, Zielinski J: Global strategy for the diagnosis, management, and prevention of chronic obstructive pulmonary disease: GOLD executive summary. Am J Respir Crit Care Med 2007, 176:532-555.

2. Gunen H, Hacievliyagil SS, Kosar F, Mutlu LC, Gulbas G, Pehlivan E, Sahin I, Kizkin O: Factors affecting survival of hospitalised patients with COPD. Eur Respir J 2005, 26:234-241

3. Moran JL, Green JV, Homan SD, Leeson RJ, Leppard PI: Acute exacerbations of chronic obstructive pulmonary disease and mechanical ventilation: a reevaluation. Crit Care Med 1998, 26:71-78

4. Seneff MG, Wagner DP, Wagner RP, Zimmerman JE, Knaus WA: Hospital and 1-year survival of patients admitted to intensive care units with acute exacerbation of chronic obstructive pulmonary disease. JAMA 1995, 274:1852-1857.

5. Lightowler JV, Wedzicha JA, Elliott MW, Ram FS: Non-invasive positive pressure ventilation to treat respiratory failure resulting from exacerbations of chronic obstructive pulmonary disease: Cochrane systematic review and meta-analysis. BMJ 2003, 326:185.

6. Rivera-Fernandez R, Navarrete-Navarro P, Fernandez-Mondejar E, RodriguezElvira M, Guerrero-Lopez F, Vazquez-Mata G: Six-year mortality and quality of life in critically ill patients with chronic obstructive pulmonary disease. Crit Care Med 2006, 34:2317-2324.

7. Gursel G: Determinants of the length of mechanical ventilation in patients with COPD in the intensive care unit. Respiration 2005, 72:61-67.

8. Nevins ML, Epstein SK: Predictors of outcome for patients with COPD requiring invasive mechanical ventilation. Chest 2001, 119:1840-1849.

9. Menzies R, Gibbons W, Goldberg P: Determinants of weaning and survival among patients with COPD who require mechanical ventilation for acute respiratory failure. Chest 1989, 95:398-405.

10. Quinnell TG, Pilsworth S, Shneerson JM, Smith IE: Prolonged invasive ventilation following acute ventilatory failure in COPD: weaning results, survival, and the role of noninvasive ventilation. Chest 2006, 129:133-139.

11. Webster NR, Kulkarni V: Metabolic alkalosis in the critically ill. Crit Rev Clin Lab Sci 1999, 36:497-510.

12. Gallagher TJ: Metabolic alkalosis complicating weaning from mechanical ventilation. South Med J 1979, 72:786-787.

13. Gluck SL: Acid-base. Lancet 1998, 352:474-479.

14. Rose B: Respiratory acidosis. In Clinical Physiology of Acid-Base and Electrolytes Disorders. Edited by Rose B. New York: McGraw-Hill; 1984:440-461.

15. Faisy C, Mokline A, Sanchez O, Tadie JM, Fagon JY: Effectiveness of acetazolamide for reversal of metabolic alkalosis in weaning COPD patients from mechanical ventilation. Intensive Care Med 2010, 36:859-863.

16. Heming N, Faisy C, Urien S: Population pharmacodynamic model of bicarbonate response to acetazolamide in mechanically ventilated chronic obstructive pulmonary disease patients. Crit Care 2011, 15:R213.

17. Wilson RF, Gibson D, Percinel AK, Ali MA, Baker G, LeBlanc LP, Lucas C: Severe alkalosis in critically ill surgical patients. Arch Surg 1972, 105:197-203.

18. Hodgkin JE, Soeprono FF, Chan DM: Incidence of metabolic alkalemia in hospitalized patients. Crit Care Med 1980, 8:725-728.

19. Krintel JJ, Haxholdt OS, Berthelsen P, Brockner J: Carbon dioxide elimination after acetazolamide in patients with chronic obstructive pulmonary disease and metabolic alkalosis. Acta Anaesthesiol Scand 1983, 27:252-254.

20. Berthelsen P: Cardiovascular performance and oxyhemoglobin dissociation after acetazolamide in metabolic alkalosis. Intensive Care Med 1982, 8:269-274.

21. Holland AE, Wilson JW, Kotsimbos TC, Naughton MT: Metabolic alkalosis contributes to acute hypercapnic respiratory failure in adult cystic fibrosis. Chest 2003, 124:490-493.

22. Tobin MJ, Jubran A: Weaning from mechanical ventilation. In Principles and Practice of Mechanical Ventilation. 2nd edition. Edited by Tobin MJ. New York: McGraw-Hill; 2006:1185-1220.

23. Khanna A, Kurtzman NA: Metabolic alkalosis. Respir Care 2001, 46:354-365.

24. Brimioulle S, Berre J, Dufaye P, Vincent JL, Degaute JP, Kahn RJ: Hydrochloric acid infusion for treatment of metabolic alkalosis associated with respiratory acidosis. Crit Care Med 1989, 17:232-236.

25. Berthelsen P, Gothgen I, Husum B, Jacobsen E: Oxygen uptake and carbon dioxide elimination after acetazolamide in the critically ill. Intensive Care Med 1985, 11:26-29.

26. Pastorekova S, Parkkila S, Pastorek J, Supuran CT: Carbonic anhydrases: current state of the art, therapeutic applications and future prospects. J Enzyme Inhib Med Chem 2004, 19:199-229.

27. Temperini C, Cecchi A, Scozzafava A, Supuran CT: Carbonic anhydrase inhibitors. Comparison of chlorthalidone, indapamide, trichloromethiazide, and furosemide X-ray crystal structures in adducts with isozyme II, when several water molecules make the difference. Bioorg Med Chem 2009, 17:1214-1221.

28. Kiwull-Schone HF, Teppema L, Kiwull PJ: Low-dose acetazolamide does affect respiratory muscle function in spontaneously breathing anesthetized rabbits. Am J Respir Crit Care Med 2001, 163:478-483.

29. Sterling D, Alvarez BV, Casey JR: The extracellular component of a transport metabolon. Extracellular loop 4 of the human $\mathrm{AE} 1 \mathrm{Cl}-/ \mathrm{HCO} 3-$ exchanger binds carbonic anhydrase IV. J Biol Chem 2002, 277:25239-25246.

30. Swenson ER: Carbonic anhydrase inhibitors and ventilation: a complex interplay of stimulation and suppression. Eur Respir J 1998, 12:1242-1247.

31. Supuran CT: Carbonic anhydrases: novel therapeutic applications for inhibitors and activators. Nat Rev Drug Discov 2008, 7:168-181.

32. Schelegle ES, Green JF: An overview of the anatomy and physiology of slowly adapting pulmonary stretch receptors. Respir Physiol 2001, 125:17-31.

33. Ravi K: Effect of carbon dioxide on the activity of slowly and rapidly adapting pulmonary stretch receptors in cats. J Auton Nerv Syst 1985 12:267-277.

34. Sant'Ambrogio G, Miserocchi G, Mortola J: Transient responses of pulmonary stretch receptors in the dog to inhalation of carbon dioxide. Respir Physiol 1974, 22:191-197.

35. Matsumoto S, Okamura H, Suzuki K, Sugai N, Shimizu T: Inhibitory mechanism of $\mathrm{CO} 2$ inhalation on slowly adapting pulmonary stretch receptors in the anesthetized rabbit. J Pharmacol Exp Ther 1996, 279:402-409

36. Teppema $\perp$, Dahan A: Acetazolamide and breathing. Does a clinical dose alter peripheral and central CO(2) sensitivity? Am J Respir Crit Care Med 1999, 160:1592-1597.

37. Brechue WF, Koceja DM, Stager JM: Acetazolamide reduces peripheral afferent transmission in humans. Muscle Nerve 1997, 20:1541-1548.

38. Swenson ER, Maren TH: A quantitative analysis of $\mathrm{CO} 2$ transport at rest and during maximal exercise. Respir Physiol 1978, 35:129-159.

39. Cogan MG, Maddox DA, Warnock DG, Lin ET, Rector FC Jr.: Effect of acetazolamide on bicarbonate reabsorption in the proximal tubule of the rat. Am J Physiol 1979, 237:F447-454.

40. Lucci MS, Warnock DG, Rector FC Jr.: Carbonic anhydrase-dependent bicarbonate reabsorption in the rat proximal tubule. Am J Physiol 1979, 236:F58-65.

41. Moviat M, Pickkers P, van der Voort PH, van der Hoeven JG: Acetazolamidemediated decrease in strong ion difference accounts for the correction of metabolic alkalosis in critically ill patients. Crit Care 2006, 10:R14.

42. Kassamali R, Sica DA: Acetazolamide: a forgotten diuretic agent. Cardiol Rev 2011, 19:276-278

43. Posner JB, Plum F: The toxic effects of carbon dioxide and acetazolamide in hepatic encephalopathy. J Clin Invest 1960, 39:1246-1258.

44. Uwai Y, Saito H, Hashimoto Y, Inui KI: Interaction and transport of thiazide diuretics, loop diuretics, and acetazolamide via rat renal organic anion transporter rOAT1.J Pharmacol Exp Ther 2000, 295:261-265.

45. Tzanakis N, Metzidaki G, Thermos K, Spyraki CH, Bouros D: Anaphylactic shock after a single oral intake of acetazolamide. Br J Ophthalmol 1998, 82:588.

46. Palmer BF, Alpern RJ: Metabolic alkalosis. J Am Soc Nephrol 1997, 8:1462-1469.

47. Vos PJ, Folgering HT, de Boo TM, Lemmens WJ, van Herwaarden CL: Effects of chlormadinone acetate, acetazolamide and oxygen on awake and asleep gas exchange in patients with chronic obstructive pulmonary disease (COPD). Eur Respir J 1994, 7:850-855.

48. Skatrud JB, Dempsey JA: Relative effectiveness of acetazolamide versus medroxyprogesterone acetate in correction of chronic carbon dioxide retention. Am Rev Respir Dis 1983, 127:405-412.

49. Mazur JE, Devlin JW, Peters MJ, Jankowski MA, lannuzzi MC, Zarowitz BJ: Single versus multiple doses of acetazolamide for metabolic alkalosis in critically ill medical patients: a randomized, double-blind trial. Crit Care Med 1999, 27:1257-1261.

50. Marik PE, Kussman BD, Lipman J, Kraus P: Acetazolamide in the treatment of metabolic alkalosis in critically ill patients. Heart Lung 1991, 20:455-459. 
51. Dickinson GE, Myers ML, Goldbach M, Sibbald W: Acetazolamide in the treatment of ventilatory failure complicating acute metabolic alkalosis. Anesth Analg 1981, 60:608-610.

52. ClinicalTrials.gov homepage [http://clinicaltrials.gov/ct2/home]. doi:10.1186/cc11323

Cite this article as: Heming $N$, et al:: Acetazolamide: a second wind for a respiratory stimulant in the intensive care unit? Critical Care 2012, 16:318 